Наносистели, нанолатеріали, нанотехнології Nanosistemi, Nanomateriali, Nanotehnologii 2019, т. 17, № 2, сc. 321-341
(C) 2019 ІМФ (Інститут металофізики ім. Г. В. Курдюмова НАН України) Надруковано в Україні. Фотокопіювання дозволено тільки відповідно до ліцензії

PACS numbers: 07.85.Nc, 79.60.Jv, 81.05.Zx, 82.75.Fq, 82.80.Pv, 87.64.-t, 87.85.Qr

\title{
Quantum Nature of Stability Mechanisms of Calcium Apatite Structure
}

\author{
L. I. Karbovska, V. L. Karbivskyy, N. A. Kurgan, A. O. Romansky, \\ O. Ya. Kuznetsova, and A. P. Soroka
}

G. V. Kurdyumov Institute for Metal Physics of the N.A.S. of Ukraine, 36 Academician Vernadsky Boulevard, UA-03142 Kyiv, Ukraine

The role of the nascent $d$-shell of calcium in the formation of the anomalous features of calcium apatite depending on the composition, synthesis conditions, changes in dimensionality and topology of key elements is investigated. A detailed analysis of the electronic structure of calcium apatite is performed with spectral and theoretical methods. The limitations of the application of quantum-mechanical calculations using the methods of the density functional theory to the description of the long-range component of the interaction of calcium with the surroundings are established. In turn, experimental data indicate that the stability of the structure of apatite is determined largely by the two-valley effective potential of calcium $d$-electrons. In various calcium compounds, atomic effects play a significant role in forming the shape of the $L_{\alpha}$-spectra of calcium, and, as a result, the participation of $d$-states of calcium in bond formation is levelled by their significant localization, apparently, in the inner valley of the effective potential.

Досліджено роль $d$-оболонки Кальцію, що зароджується, у формуванні аномальних особливостей апатиту кальцію в залежності від складу, умов синтези, змін вимірности та топології ключових елементів. Спектральними та теоретичними методами проведено детальну аналізу електронної будови апатитів кальцію та встановлено обмеженість застосування квантово-механічних розрахунків з використанням метод теорії функціоналу густини до опису далекосяжної складової взаємодії Кальцію з оточенням. У свою чергу, експериментальні дані вказують на те, що стійкість структури апатиту багато в чому визначається дводолинним ефективним потенціялом $d$-електронів Кальцію. У різних сполуках Кальцію у формуванні форми кривих $L_{\alpha}$-спектрів Кальцію значну роль відіграють атомові ефекти, i, як наслідок, участь $d$-станів Кальцію в утворенні зв'язків нівельовано їх значною локалізацією, швидше за 
все, у внутрішній долині ефективного потенціялу.

Исследована роль зарождающейся $d$-оболочки кальция в формировании аномальных особенностей апатита кальция в зависимости от состава, условий синтеза, изменений размерности и топологии ключевых элементов. Спектральными и теоретическими методами проведён детальный анализ электронного строения апатитов кальция и установлена ограниченность применения квантово-механических расчётов с использованием методов теории функционала плотности к описанию дальнодействующей составляющей взаимодействия кальция с окружением. В свою очередь, экспериментальные данные указывают на то, что устойчивость структуры апатита во многом определяется двухдолинным эффективным потенциалом $d$-электронов кальция. В различных соединениях кальция в формировании формы кривых $L_{\alpha}$-спектров кальция значительную роль играют атомные эффекты, и, как следствие, участие $d$-состояний кальция в образовании связей нивелировано их значительной локализацией, по всей видимости, во внутренней долине эффективного потенциала.

Key words: quantum mechanisms, calcium $d$-shell, apatite, electronic structure.

Ключові слова: квантові механізми, $d$-оболонка кальцію, апатит, електронна структура.

Ключевые слова: квантовые механизмы, $d$-оболочка кальция, апатит, электронная структура.

(Received 15 April 2019)

\section{INTRODUCTION}

Life on Earth is inextricably connected with apatite structures. Their wide distribution in the bio- and lithosphere determines their direct influence on the processes of vital activity and various aspects of ecological, biological and technical applications. Minerals and synthetic compounds with apatite type structure form a large family: $A_{10}\left(\mathrm{TO}_{4}\right)_{6} X_{2}(A=\mathrm{Ca}, \mathrm{Sr}, \mathrm{Ba}, \mathrm{Pb}, \mathrm{Na}, \mathrm{Mn}, \mathrm{Cd}, \mathrm{Fe}, \mathrm{K}, \mathrm{Li}$, rare earth elements (REE); $T=\mathrm{P}, \mathrm{Si}, \mathrm{Ge}, \mathrm{As}, \mathrm{Cr}, \mathrm{N}, \mathrm{V}, \mathrm{S} ; X=\mathrm{F}, \mathrm{Cl}, \mathrm{OH}$, $\mathrm{O}, \mathrm{Br}, \mathrm{I}, \mathrm{CO}_{3}$ ). Interest in these compounds is determined by several reasons. First, calcium-containing apatites are close in chemical composition to the inorganic component of bone. Secondly, the possibility of a wide range of iso- and heterovalent substitutions determines the use of apatites as luminescent materials and radioactive waste disposal matrices. The significance of materials based on apatites is noted today in many areas, including biology, medicine, electronics, surface science, etc. 
The space agency NASA has adopted the Advanced Life Support program, within which comprehensive studies of apatite-like compounds are carried out in order to use them as a source of soil phosphorus and oxygen for long-term space missions and settlements on the Moon and Mars. Today, it is safe to conclude that, in modern materials science, a new direction has been formed-apatite science.

The expansion of practical applications of apatites is mainly due to the features of the atomic and electronic structure, in particular, the anomalous stability of the structure of calcium apatite in a wide range of non-stoichiometry $(\mathrm{Ca} / \mathrm{P}$ varies from $\cong 1.34$ to $\cong 1.72)$. Therefore, understanding the nature of the mechanisms for the stability of the structure of apatite and the fundamental principles of organization and management of the physicochemical properties of apatite-like structures based on calcium, according to the authors, is possible only if the role of the emerging $d$-shell of calcium in the compounds is described, depending on the composition, synthesis conditions, changes in the size and topology of key elements, as well as a detailed analysis of the electronic structure of calcium apatites.

The information accumulated in subsequent years in the scientific literature, as well as the personal experience of the authors [1], allows us to systematize and understand the anomalous features of the structure of apatite and various processes involving apatite in living tissue of organisms.

\section{STRUCTURE OF APATITE}

Crystallographic data of calcium apatites are given in many works, in particular [2-7]. For the most common calcium and phosphorus compounds with $X$ ions on the axis $c(X=\mathrm{OH}, \mathrm{F}, \mathrm{Cl})$, cell parameters are equal, respectively, $a=9.4302(5), 9.3475(3), 9.5902(6) \AA$ and $c=6.8911(2), 6.8646(1), 6.7666(2) \AA$. There are two nonequivalent crystallographic sites for $\mathrm{Ca}$, namely, $\mathrm{Ca}_{(1)}(\mathrm{Ca}$ in the column) at $z=0$ and $1 / 2$ and $\mathrm{Ca}_{(2)}$ (spiral axis of $\mathrm{Ca}$ ) at $z=1 / 4$ and $3 / 4$. Each $\mathrm{Ca}_{(1)}$ ion is surrounded by 9 oxygen atoms from $6 \mathrm{PO}_{4}$ groups $-\mathrm{CaO}_{9}$, and the $\mathrm{Ca}_{(2)}$ ion by 7 oxygen atoms from $5 \mathrm{PO}_{4}$ groups and 1 from $\mathrm{OH}$ group $-\mathrm{CaO}_{7} X$. Consequently, the composition of apatite can also be expressed as $\left[\mathrm{Ca}_{(1)}\right]_{4}\left[\mathrm{Ca}_{(2)}\right]_{6}\left(\mathrm{PO}_{4}\right)_{6}(\mathrm{OH})_{2}$.

The base of the structure of apatite consists of two types of Capolyhedra. Some of them, seven-vertex, are located according to the rule of the three-way screw along the axis $6_{3}$, moreover, the same three-way screw is formed by empty polyhedra separating them; others, nine-vertex, represent trigonal prisms with centred faces, the prisms merge with each other with their bases and form columns, in the centre of which are triple axis. Prism columns bind to 
the seven-vertexes via common oxygen atoms from $\mathrm{PO}_{4}$ tetrahedra. Hydroxyl ions are located on axis $6_{3}$.

In these compounds, the anion interacts most strongly with the atoms $M_{(2)}$, which is determined by their position in the triangular fragment. In $\mathrm{Ca}_{10}\left(\mathrm{PO}_{4}\right)_{6} X_{2}$, the $\mathrm{F}^{-}$ion is located in the plane of the triangle, while large $\mathrm{OH}^{-}$and $\mathrm{Cl}^{-}$-anions are located above and below $M_{(2)}$ triangles.

Nonstoichiometry of composition. A unique characteristic of calcium hydroxyapatite $\left(\mathrm{Ca}_{10}\left(\mathrm{PO}_{4}\right)_{6}(\mathrm{OH})_{2}\right.$, Ca-HAP) is the nonstoichiometry of its composition. The $\mathrm{Ca} / \mathrm{P}$ ratio is used as the nonstoichiometric index. For calcium apatite, this parameter can vary over a wide range from 1.30 to 1.74 . Most of the Ca-HAP powders synthesized by the 'wet' method are nonstoichiometric. Currently, to describe nonstoichiometry, formula $\mathrm{Ca}_{10-x}\left(\mathrm{HPO}_{4}\right)_{x}\left(\mathrm{PO}_{4}\right)_{6-x}(\mathrm{OH})_{2-x} n \mathrm{H}_{2} \mathrm{O}$ $(0<x<1, n=0-2.5)$ is used, suggesting a Ca deficiency. In this case, it is assumed that the local negative charge is compensated by the introduction of $\mathrm{H}^{+}$ions, leading to the formation of $\mathrm{H}_{2} \mathrm{O}$ molecules occupying the $\mathrm{OH}^{-}$positions. There is reason to believe that, in addition to the $\mathrm{Ca}^{2+}, \mathrm{PO}_{4}{ }^{3-}$ and $\mathrm{OH}^{-}$ions, in the 'wet' synthesis $\mathrm{H}_{3} \mathrm{O}^{+}, \mathrm{H}_{4} \mathrm{O}_{4}{ }^{4-}$ и $\mathrm{HPO}_{4}{ }^{2-}$ ions also participate in phase formation, replacing respectively $\mathrm{Ca}^{2+}$ and $\mathrm{PO}_{4}^{3-}$ in the Ca-HAP crystal lattice.

In recent years, many works have been devoted to the preparation of Ca-HAP with different $\mathrm{Ca} / \mathrm{P}$ ratios. Ca-HAP with a $\mathrm{Ca} / \mathrm{P}$ molar ratio of 1.74 , obtained by heating the precipitates to $1200^{\circ} \mathrm{C}$, $1300^{\circ} \mathrm{C}, 1350^{\circ} \mathrm{C}$, turned out to be, according to X-ray diffraction data, anhydrous monophase crystal structures. Crystal-chemical simulation showed that excess $\mathrm{Ca}^{2+}$ and $\mathrm{O}^{2-}$ or $\mathrm{OH}^{-}$ions can be localized in the channels of the crystal structure.

The crystal structure of Ca-HAP remains stable over a wide range of deviations from stoichiometric composition $(\mathrm{Ca}: \mathrm{P}=1.66)$, and $\mathrm{OH}^{-}$ions are stable even at relatively high temperatures (up to $1350^{\circ} \mathrm{C}$ ). Consequently, the change in the physicochemical properties of nonstoichiometric samples is largely determined by the electronic structure.

Due to the anomalous parameter of nonstoichiometry, high radiation resistance of calcium apatite is observed. The accumulation of a large number of various types of defects during irradiation leads to the formation of polycrystals and, ultimately, to the nanostructuring of the sample. It is known that for almost the entire life in the native bone of mammals, calcium apatite is in a nanodispersed state with a specific surface area of about $550 \mathrm{~m}^{2} / \mathrm{g}$. Bone nanocrystals act as a matrix for the accumulation of metal ions that are not involved in metabolism and during the lifetime are converted into massive crystals.

The anomalous stability of the structure of calcium apatite to the number of defects and the wide limits of the nonstoichiometric pa- 
rameter, according to the authors of the article, are due to the chemical nature of the atom of the element, namely, the emerging $3 d$-electron shell of calcium.

\section{NASCENT $d$-SHELL OF CALCIUM IN COMPOUNDS}

Calcium in the table of elements of the periodic law has number 20 and refers to alkaline-earth elements. In an atomic state, calcium has an electron configuration $[\mathrm{Ar}]+4 s^{2}$. However, in the metallic state and in all compounds, calcium has a significant suboccupancy of $d$-states, which is detected by spectral methods. Therefore, part of the valence electron density is promoted to the $d$-band.

The lack of systematization of information about the phenomenon of the collapse of the wave functions of electrons in atoms is one of the reasons why it is still relatively little known and is not always taken into account when studying the X-ray spectra of atoms. Although this phenomenon occurs only in the case of certain elements, when the atom configuration contains an excited electron with $l \geq 2$ or for a relatively narrow interval of near-threshold energies, however, in these cases, it can lead to significant effects and affect various characteristics of atoms. It is known [8] that the collapse of an electron occurs in the case of an element that in the periodic table precedes an element that contains this electron in the normal configuration of an atom. Calcium, preceding scandium, in which the $d$-electron is in the normal configuration, is an element with a possible collapse of the $d$-electron in the crystal lattice.

For the $d$-electron of calcium (Fig. 1), there are two minima on

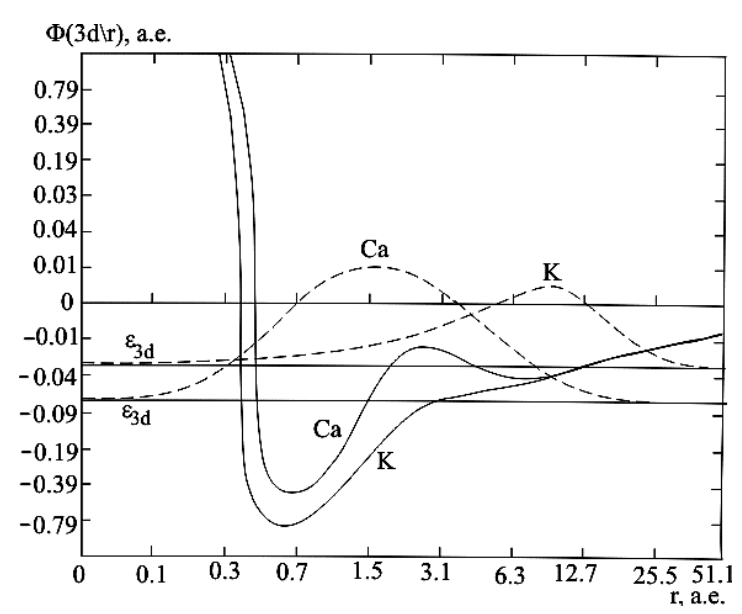

Fig. 1. Collapse of the $3 d$-electron wave function [8]. The solid line-the effective potential, the dashed line-the radial wave function. 
the effective potential curve.

During the collapse of the $d$-electron, the overlap of the $3 d$-radial wave function with the $3 p$-electron function significantly increases. This leads to an increase in the electrostatic interaction between these shells. Consequently, the collapse of the $d$-electron in the $3 p^{5} 3 d$ isoelectronic series leads to an increase in the role of the electrostatic interaction in comparison with the spin-orbit interaction. In comparison with potassium, calcium has a significant drawdown of the position of the maximum of the radial wave function of the $d$-electron from $\cong 5.0 \AA$ to $\cong 0.7 \AA$. Consequently, the presence of two valleys on the effective potential curve of $3 d$-electrons of calcium may have a consequence in the anomalous stability of the apatite structure to defects and explain the wide limits of the nonstoichiometric parameter.

\section{EXPERIMENTAL AND CALCULATED X-RAY EMISSION BANDS OF CALCIUM APATITES}

For many decades, researchers have been trying to determine the nature of the behaviour of calcium $d$-electrons in various compounds. The core character of the $d$-shell of calcium was the object of research in a number of papers, in particular [8-9], and is explained by the balance between the centrifugal potential, the Coulomb and spin-orbit interactions in the vicinity of the atomic sphere of calcium. In the case of filling the $3 d$-shell of an electron, it can be either localized in the inner part of the atom, or located in the outer valley of the effective potential.

Atomic and solid effects in the absorption spectra of calcium for metallic calcium and simple compounds were considered in [10]. Analysis of the literature data and our results allows suggesting that the atomic effects in the studied substances play a significant role in the formation of the form of calcium $L_{\alpha}$-spectra. This is confirmed by the spectra of the quantum yield of photoemission, which show a significant similarity of the spectra for completely different compounds - carbonate and fluoroapatite of calcium, as well as the spectra given in publications [11-21].

Comparison of the obtained $L_{\alpha}$-spectra of calcium in compounds (Fig. 2) and $L_{2,3}$-spectra of the quantum yield of photoemission (Fig. 3 ), which showed their little change, allows to suggest that the $3 d$ electron is localized in the inner valley of the effective potential.

In the works of V. V. Nemoshkalenko [22], it was conducted a comparative analysis of X-ray, optical and X-ray-electronic data with a theoretical calculation, which showed that the calculation in general terms correctly describes the energy structure of calcium fluoride. 


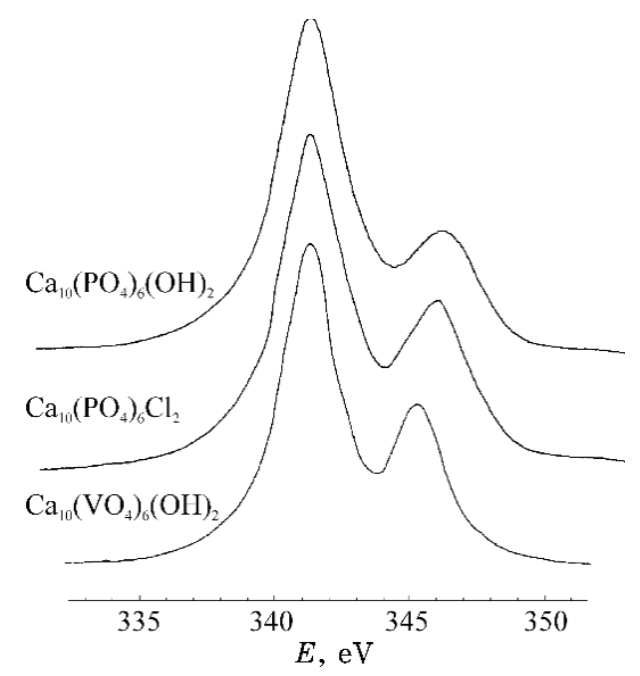

Fig. 2. Ca $L_{\alpha}$-bands in compounds.

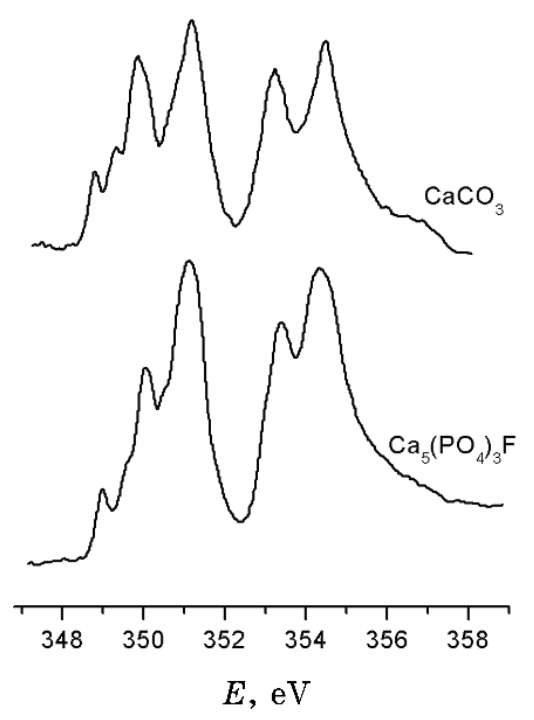

Fig. 3. $\mathrm{Ca} L_{2,3}$-spectra of the quantum yield of photoemission.

At the same time, studies of the spectrum of the quantum yield in the region of the $L_{I I}, L_{I I I}$ absorption edges of $\mathrm{Ca}$ in $\mathrm{CaF}_{2}$ revealed the presence of narrow selective maxima, which are not explainable within the framework of theoretical calculations. These maxima are higher from the bottom of the conduction band for 5 and $3 \mathrm{eV}$, respectively. Their width at half-maximum intensity is $0.1-0.2 \mathrm{eV}$. Apparently, these maxima reflect transitions to vacant $d$-states lo- 
calized near calcium atoms.

We obtained the X-ray emission bands calculated by the density functional theory (DFT). The analytical form of the X-ray emission bands was determined as the product of the corresponding partial densities of electron states that are involved in the transition from the valence band to the core level and the probability functions of the transition between levels. The last is determined by all zones that fall into a given energy interval and the wave function of the corresponding core level, which is also determined by calculation. For this purpose, a full-electron full potential LAPW + lo method and a generalized gradient approximation (Perdew-BurkeErnzerhof exchange-correlation potential) were used within the framework of DFT.

When constructing theoretical X-ray emission bands of Ca atoms, one must take into account the presence of two non-equivalent positions of $\mathrm{Ca}$ atoms $-\mathrm{Ca}_{(1)}$ and $\mathrm{Ca}_{(2)}$. Figures 4,5 show the calculated curves of $K$-bands of calcium of the first and second non-equivalent position and theoretical X-ray emission $K$-band of calcium in the compound $\mathrm{Ca}_{10}\left(\mathrm{PO}_{4}\right)_{6}(\mathrm{OH})_{2}$ obtained by adding the first and second curves and experimental $K$-band calcium. There is a good agreement between the experiment and the calculation. The main differences
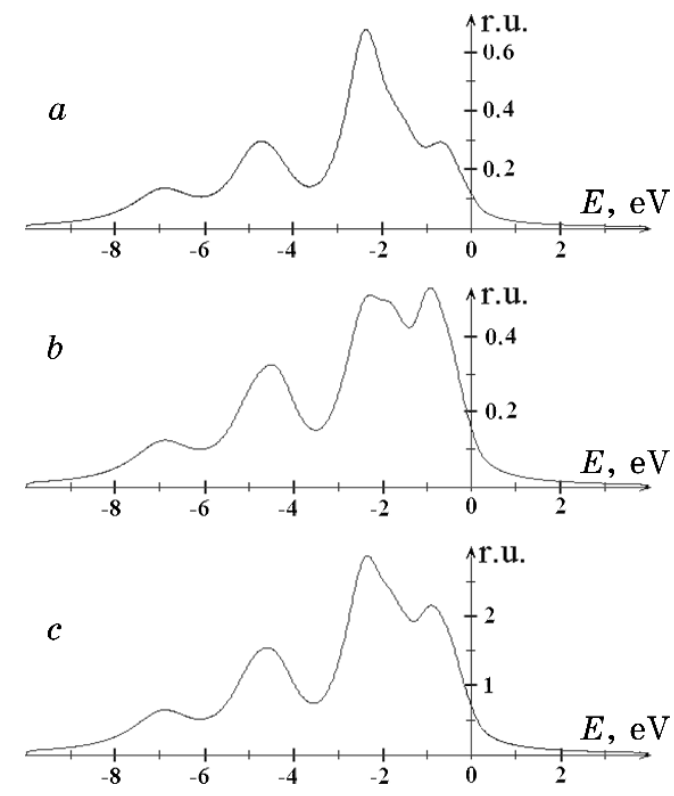

Fig. 4. The contributions of the first $(a)$ and second (b) non-equivalent calcium atoms, and the theoretical $K$-band of calcium $(c)$ in the compound $\mathrm{Ca}_{10}\left(\mathrm{PO}_{4}\right)_{6}(\mathrm{OH})_{2}$. 


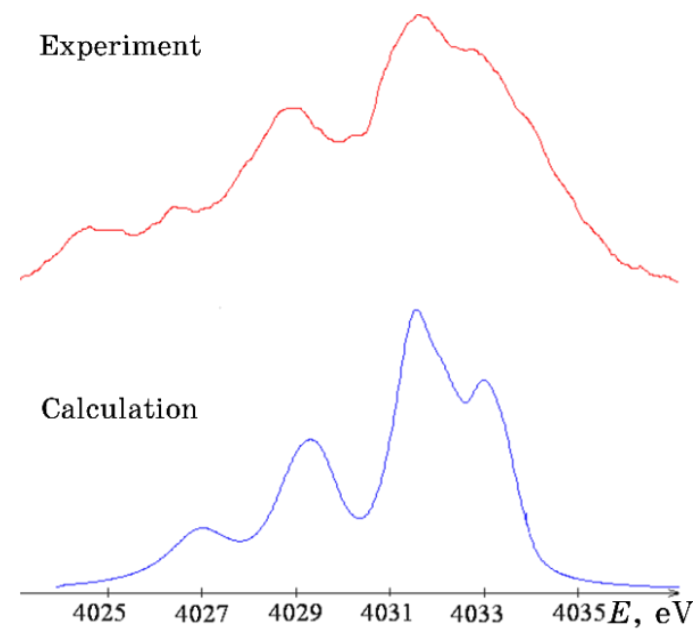

Fig. 5. Theoretical and experimental $K$-bands of calcium in the compound $\mathrm{Ca}_{10}\left(\mathrm{PO}_{4}\right)_{6}(\mathrm{OH})_{2}$.
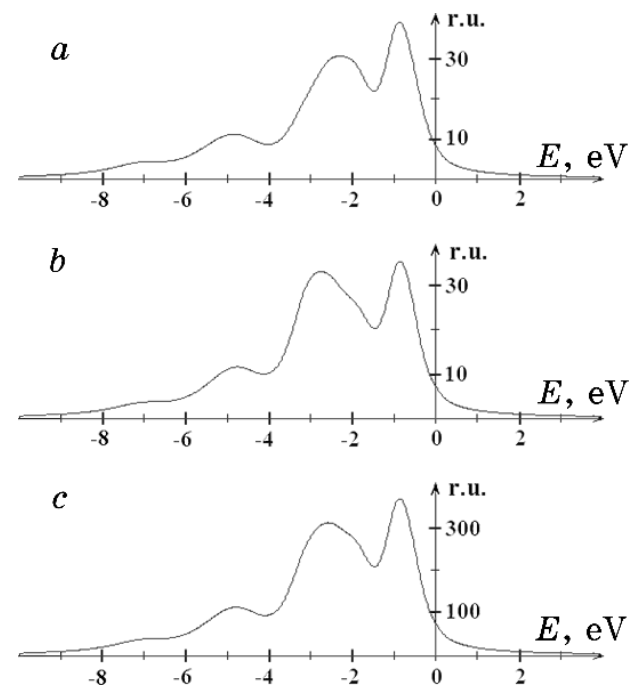

Fig. 6. Contributions of the first and second non-equivalent calcium atoms, and theoretical $L_{I I}$-band of calcium in the compound $\mathrm{Ca}_{10}\left(\mathrm{PO}_{4}\right)_{6} \mathrm{~F}_{2}$.

of the $4 p$-states of calcium atoms between the first and second nonequivalent positions of the metal are observed in the region of about $2 \mathrm{eV}$ relative to the level of the upper occupied level-HOMO.

$L_{I I, I I I}$-bands of Ca were obtained by adding the $L_{I I}$ and $L_{I I I}$ bands. The first is shifted relative to the second by the magnitude of the spin-orbit splitting of the energy level of Ca $2 p$. Figure 6 shows the 
theoretically calculated contribution of the first non-equivalent position of the Ca atom to the Ca $L_{I I}$-band (Fig. 6, a), contribution of the second non-equivalent position of the $\mathrm{Ca}$ atom to the $\mathrm{Ca} L_{I I}$-band (Fig. 6, b) and calculated $\mathrm{Ca} L_{I I}$-spectrum of the compound $\mathrm{Ca}_{10}\left(\mathrm{PO}_{4}\right)_{6} \mathrm{~F}_{2}$ (Fig. 6, c) obtained by averaging the analytical form of the first and second graphs, taking into account the number of $\mathrm{Ca}$ atoms corresponding to a given non-equivalent position.
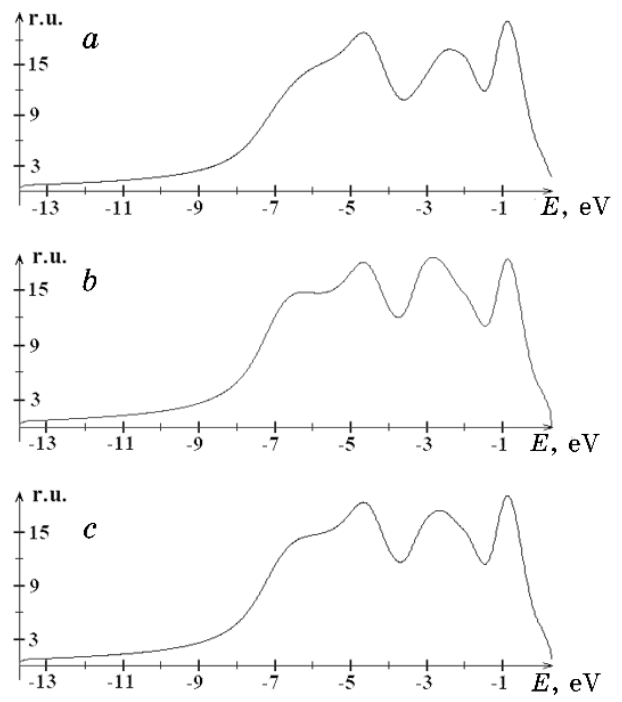

Fig. 7. Contributions of the first and second non-equivalent positions of the calcium atom, and the theoretical $L_{I I, I I I}$-band of calcium in the compound $\mathrm{Ca}_{10}\left(\mathrm{PO}_{4}\right)_{6} \mathrm{~F}_{2}$.

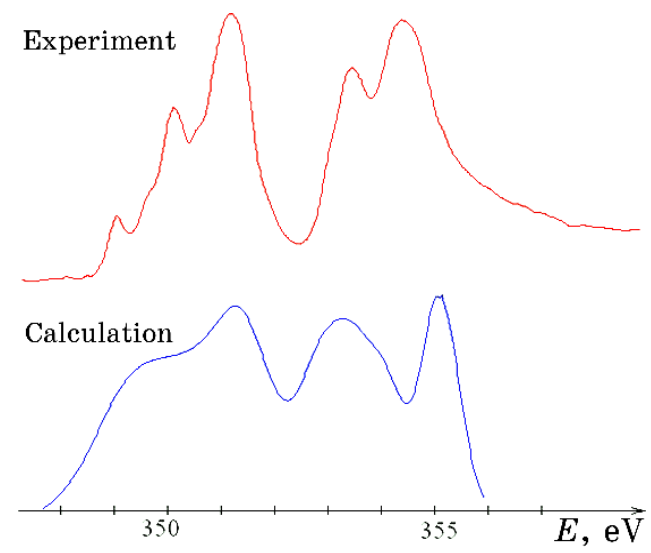

Fig. 8. Theoretical and experimental $L_{I I, I I I}$-bands of calcium in the compound $\mathrm{Ca}_{10}\left(\mathrm{PO}_{4}\right)_{6} \mathrm{~F}_{2}$. 
The theoretically calculated difference in the energy of $\mathrm{Ca}_{(1)} 2 p_{3 / 2}$ and $\mathrm{Ca}_{(1)} 2 p_{1 / 2}$ levels is $3.69 \mathrm{eV}$ and is within $0.1 \mathrm{eV}$ deviations from the experiment [2]. This value is the same for the first and second non-equivalent positions of the calcium atom. By default, in the WIEN code, the intensity ratio of the $L_{I I}$ and $L_{I I I}$ bands is 2.0 , since the number of $2 p_{3 / 2}$-electrons is twice the number of electrons of $\mathrm{Ca}$ $2 p_{1 / 2}$. However, in order to maximize the agreement between the theoretical and experimental forms of the $L_{I I, I I}$-curves of calcium, a factor of 1.44 was used.

Figure 7 shows the theoretically calculated contribution of the first non-equivalent position of the $\mathrm{Ca}$ atom to the $\mathrm{Ca} L_{I I, I I}$-band (Fig. 7, a), contribution of the second non-equivalent position of the $\mathrm{Ca}$ atom to the $\mathrm{Ca} L_{I I, I I}$-band (Fig. $7, b$ ) and theoretically calculated Ca $L_{I I, I I I}$-spectrum of the compound $\mathrm{Ca}_{10}\left(\mathrm{PO}_{4}\right)_{6} \mathrm{~F}_{2}$ (Fig. 7, c).

Figure 8 presents a comparison of the theoretical and experimental $L_{I I, I I I}$-bands of calcium in the compound $\mathrm{Ca}_{10}\left(\mathrm{PO}_{4}\right)_{6} \mathrm{~F}_{2}$. The main differences in the shape of these curves are observed in the energy range from 349.0 to $352.0 \mathrm{eV}$.

The calculated and experimental X-ray $K_{\beta}$-spectra of phosphorus in the compound $\mathrm{Ca}_{10}\left(\mathrm{PO}_{4}\right)_{6}(\mathrm{OH})_{2}$ are shown in Fig. 9.

The curves of the $K_{\beta}$-bands consist of two peaks - the main maximum and the long-wave feature. The calculation significantly underestimates the distance between them and therefore the long-wave feature on the calculated curves is poorly pronounced. This is due to the fact that the phosphorus atom is coordinated by 4 oxygen atoms with very short bonds $(\cong 1.51 \AA)$. In this regard, the radius of the MT sphere for the phosphorus atom should be chosen rather small-about $0.76 \AA$. However, the electron density of the phosphorus atom, especially the valence $p$-density, which participates in the formation of the $K_{\beta}$-band of phosphorus, goes beyond the limits of

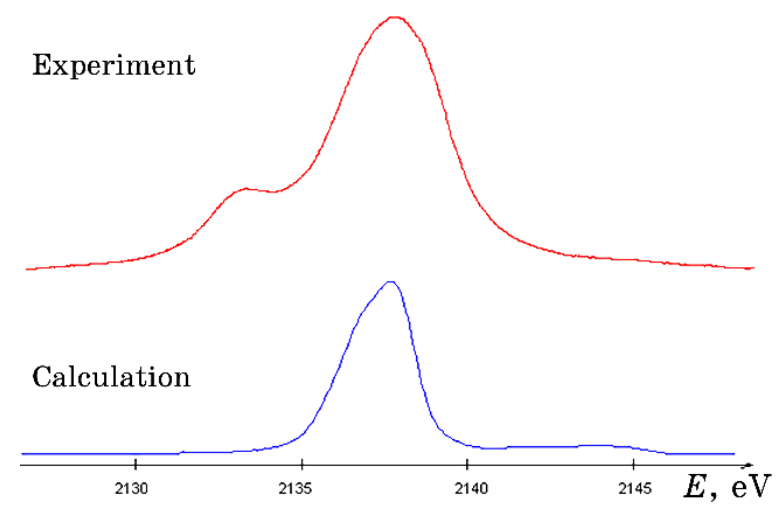

Fig. 9. $K_{\beta}$-bands of phosphorus in the compound $\mathrm{Ca}_{10}\left(\mathrm{PO}_{4}\right)_{6}(\mathrm{OH})_{2}$. 
the geometric $\mathrm{PO}_{4}$-tetrahedron. Therefore, the small radius of the MT-sphere for the phosphorus atom, when calculating the X-ray emission bands, does not allow a detailed description of the valence band of phosphorus. The presence of the long-wavelength feature in the experimental $K_{\beta}$-bands of phosphorus determines the long-range interaction of the phosphate ion with the environment, in particular, with various types of calcium cations. This fact significantly affects the stability of the crystal lattice of calcium apatite.

Figure 10 shows the theoretical and calculated X-ray emission $K_{\alpha}$-bands of fluorine in the compound $\mathrm{Ca}_{10}\left(\mathrm{PO}_{4}\right)_{6} \mathrm{~F}_{2}$. As in other theoretically calculated X-ray emission bands, in this case, the calculation underestimates the distance between the peaks on the curve of the $K_{\alpha}$-band of fluorine. This fact indicates a significant underestimation of the fluorine-calcium interaction in such calculation.

The presence of a short-wave feature on the experimental spectrum of the $K_{\alpha}$-band of fluorine, which corresponds in a single energy scale to the maximum of the $3 d$-states of calcium in the metal, indicates a significant interaction of fluorine with calcium.

When constructing the theoretical X-ray emission bands of the oxygen atom of the $\mathrm{Ca}_{10}\left(\mathrm{PO}_{4}\right)_{6} \mathrm{~F}_{2}$ compound, it is necessary to take into account the contribution of three non-equivalent $\mathrm{PO}_{4^{-}}$ tetrahedron $\mathrm{O}$ atoms. According to the results of the calculations, the first non-equivalent oxygen atom has the lowest energy $\mathrm{O} 1 s$.

The positions of the core $\mathrm{O} 1 \mathrm{~s}$ levels on the energy scale for the second and third non-equivalent positions of the oxygen atom are closer to the vacuum level in comparison with the first non-

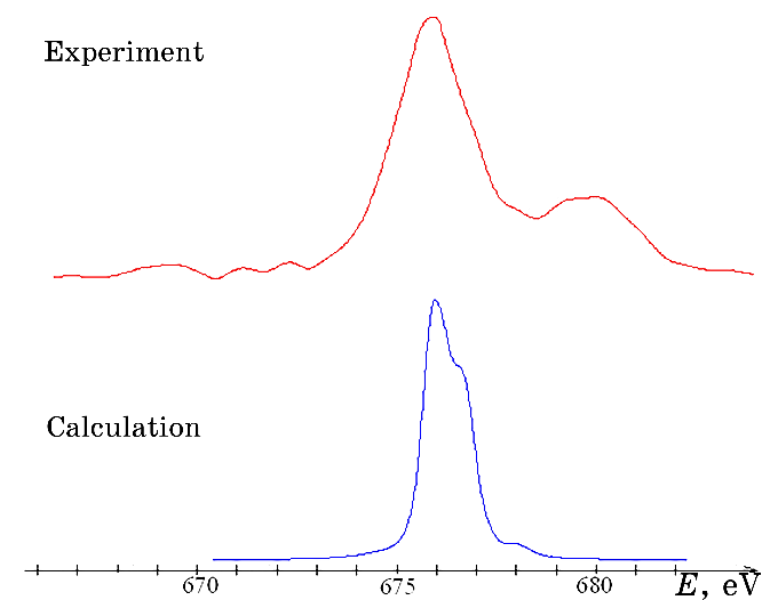

Fig. 10. Experimental and theoretical $K_{\alpha}$-bands of fluorine in the compound $\mathrm{Ca}_{10}\left(\mathrm{PO}_{4}\right)_{6} \mathrm{~F}_{2}$. 

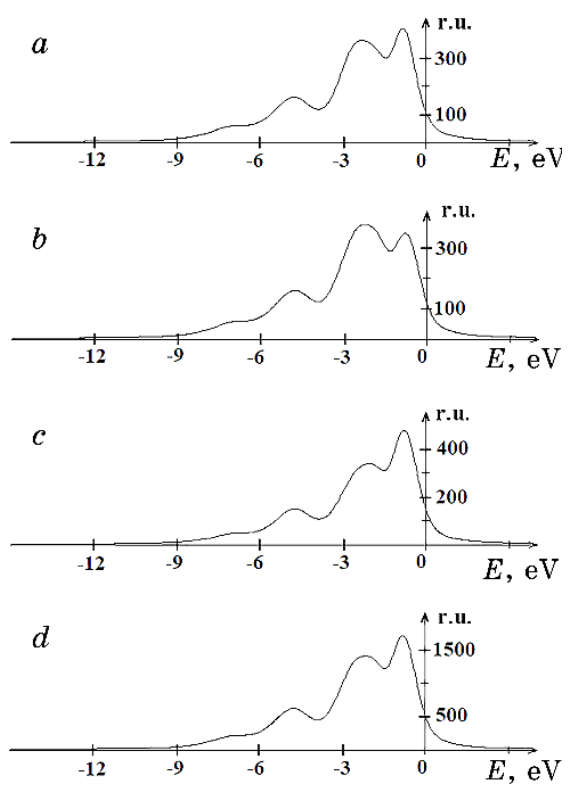

Fig. 11. Contributions from three non-equivalent oxygen atoms and theoretical $K_{\alpha}$-band of oxygen in the compound $\mathrm{Ca}_{10}\left(\mathrm{PO}_{4}\right)_{6} \mathrm{~F}_{2}$.

equivalent position, but this difference is small, within $0.2 \mathrm{eV}$. Contributions from three non-equivalent oxygen atoms with allowance for the above-mentioned shifts $(a, b$, and $c)$, as well as the resulting calculated $K_{\alpha}$-band of oxygen in the compound $\mathrm{Ca}_{10}\left(\mathrm{PO}_{4}\right)_{6} \mathrm{~F}_{2}(d)$ are presented in Fig. 11.

Figure 12 compares the theoretical and experimental $K_{\alpha}$-band of oxygen in the compound $\mathrm{Ca}_{10}\left(\mathrm{PO}_{4}\right)_{6} \mathrm{~F}_{2}$. There is a characteristic underestimation of the distance between the peaks, especially in the region of $520.0 \mathrm{eV}$. In general, as can be seen from the figures, there is a satisfactory agreement between the experimental oxygen spectra and the theoretically calculated ones. There is only one short-wave feature in the experimental spectrum, which is not reflected by a theoretical approach. In a single energy scale, this feature corresponds to the position of the main maximum of the $K$ band of calcium and reflects, respectively, $2 p-3 d, 4 p$ interaction of oxygen with calcium. As in the case of fluorine, the small radius of the MT sphere does not allow to describe fully the long-range component of the interaction of oxygen with calcium.

The presence of short-wave components in the spectra of oxygen and fluorine may indirectly indicate an important feature of the long-range interaction of calcium with the surrounding atoms.

A similar procedure of averaging over the contributions to the 


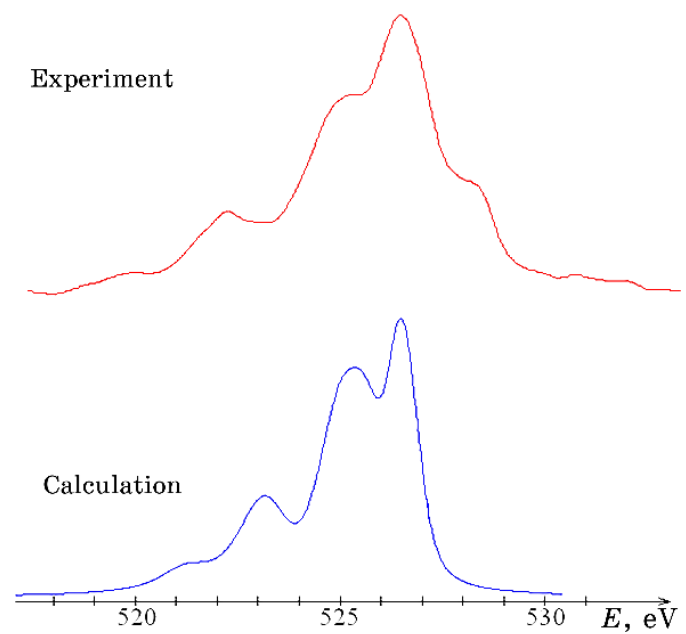

Fig. 12. Experimental and theoretical $K_{\alpha}$-bands of oxygen in the compound $\mathrm{Ca}_{10}\left(\mathrm{PO}_{4}\right)_{6} \mathrm{~F}_{2}$.

$K_{\alpha}$-bands of oxygen was carried out for the compound $\mathrm{Ca}_{10}\left(\mathrm{PO}_{4}\right)_{6}(\mathrm{OH})_{2}$. Here, in addition to the contribution from three non-equivalent oxygen atoms of $\mathrm{PO}_{4}$-tetrahedra, oxygens of $\mathrm{OH}$ groups also contribute. The electron density of valence electrons on any of the three non-equivalent oxygen atoms of the $\mathrm{PO}_{4}$ tetrahedron is lower than that of the oxygen atom of the OH-group. The contributions from the second and third non-equivalent oxygen atom are shifted by 0.1 and $0.2 \mathrm{eV}$, respectively, and these results $(a, b, c$, and $d)$ are presented in Fig. 13. The resulting theoretically calculated $K_{\alpha}$-band of the oxygen of the compound $\mathrm{Ca}_{10}\left(\mathrm{PO}_{4}\right)_{6}(\mathrm{OH})_{2}$ is shown in Fig. 13, e.

The experimental and theoretical $K_{\alpha}$-band of the oxygen of the compound $\mathrm{Ca}_{10}\left(\mathrm{PO}_{4}\right)_{6}(\mathrm{OH})_{2}$ is shown in Fig. 14. A comparison of the $K_{\alpha}$-bands of oxygen for fluor- and hydroxyapatite (Figs. 11-14) shows a significant similarity of the curves describing the electronic states of the oxygen of both compounds. Given the fact that oxygen in the structure of apatite is about $\cong 50 \%$ of atoms and, therefore, determines the general patterns of formation of the valence band, we can say with certainty that this is in some sense an oxygen matrix [1].

\section{QUANTUM-MECHANICAL CALCULATIONS OF THE ATOMIC STRUCTURE OF APATITES $\mathrm{Ca}_{10}\left(\mathrm{PO}_{4}\right)_{6} X_{2}$, WHERE $X \quad \mathrm{~F}, \mathrm{Cl}, \mathrm{OH}$}

To analyse the atomic structure of calcium apatites, we applied the 

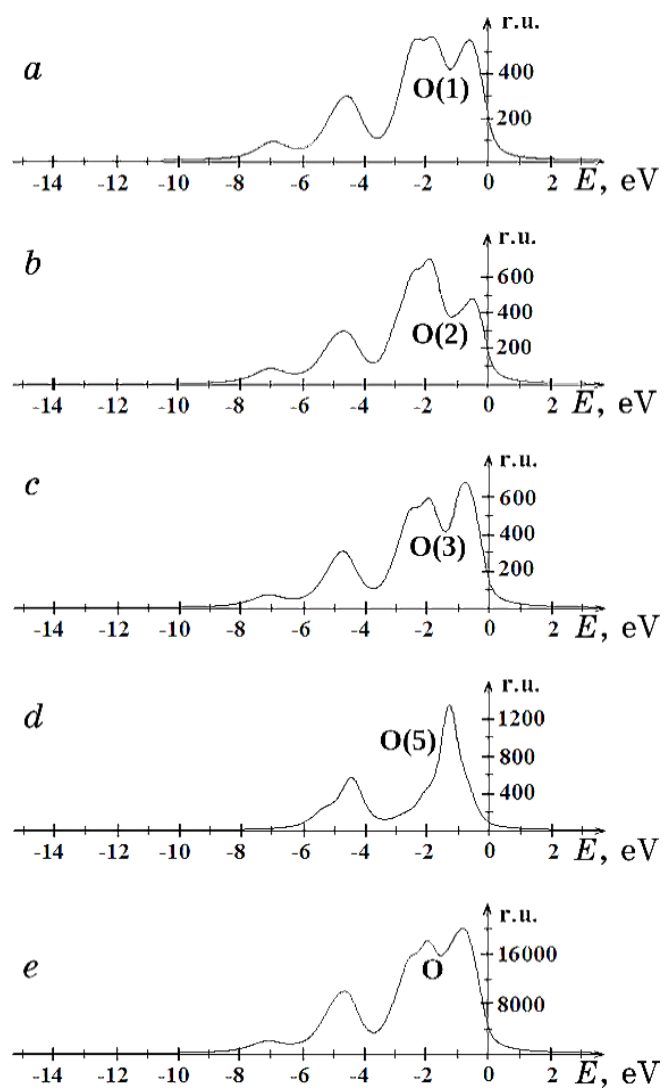

Fig. 13. Contributions from four non-equivalent oxygen atoms of the $\mathrm{PO}_{4}$ tetrahedra and $\mathrm{OH}$-groups, and the theoretical $K_{\alpha}$-band of oxygen in the compound $\mathrm{Ca}_{10}\left(\mathrm{PO}_{4}\right)_{6}(\mathrm{OH})_{2}$.

full potential LAPW + lo method within the framework of the generalized gradient approximation using the exchange-correlation potential in the form of the Perdew-Burke-Ernzerhof approximation. The results show that, for all calcium apatites studied by us, the lengths of $\mathrm{P}-\mathrm{O}$ bonds on the length scale are arranged in the same order, namely, the length $\mathrm{P}-\mathrm{O}_{(1)}<$ length $\mathrm{P}-\mathrm{O}_{(3)}<$ length $\mathrm{P}-\mathrm{O}_{(2)}(\mathrm{Ta}-$ ble). Such a general tendency for the bond lengths of all calcium apatites studied by us indicates that the replacement of anions on the sixth-order axes does not significantly change the spatial orientation of $\mathrm{PO}_{4}$-tetrahedra.

When replacing anions located on the sixth order axes, for the surroundings of the calcium atom, we obtained the following pattern consisting in that the length of the $\mathrm{Ca}_{(1)}-\mathrm{O}_{(1)}$ increase in a series of compounds $\mathrm{Ca}_{10}\left(\mathrm{PO}_{4}\right)_{6} \mathrm{~F}_{2} \rightarrow \mathrm{Ca}_{10}\left(\mathrm{PO}_{4}\right)_{6}(\mathrm{OH})_{2} \rightarrow \mathrm{Ca}_{10}\left(\mathrm{PO}_{4}\right)_{6} \mathrm{Cl}_{2}$, 


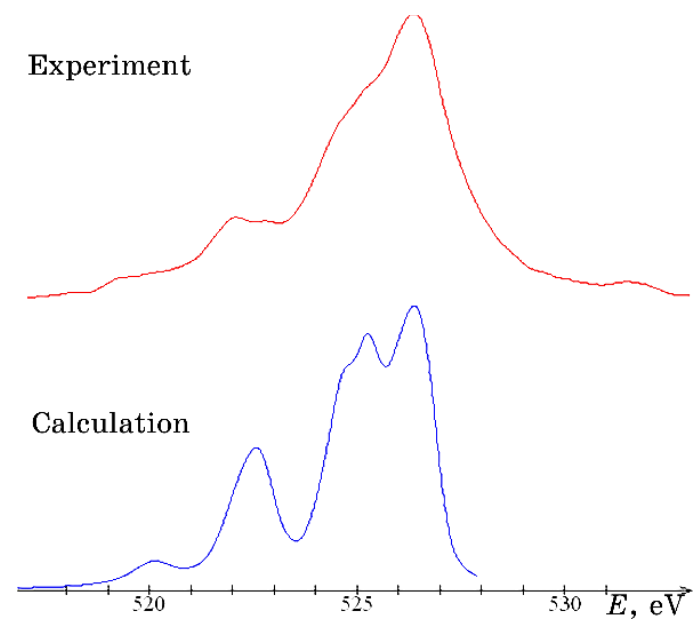

Fig. 14. Experimental and theoretical $K_{\alpha}$-bands of oxygen in the compound $\mathrm{Ca}_{10}\left(\mathrm{PO}_{4}\right)_{6}(\mathrm{OH})_{2}$.

and the reverse pattern was recorded for $\mathrm{Ca}_{(1)}-\mathrm{O}_{(2)}$ bonds.

The following factors affect the change in $\mathrm{Ca}_{(2)}-\mathrm{O}$ bond lengths, when replacing all anions located on axes of the sixth order.

Firstly, the calcium atoms of the second non-equivalent position are coordinated by various $X$ anions. Therefore, an increase in the electronegativity of anions located on the sixth-order axes leads to an increase in the outflow of electron charge from anions $X$ to the calcium atoms of the second non-equivalent position, which should lead to a decrease in the electron charge outflow from $\mathrm{Ca}_{(2)}$ atoms to the nearest oxygen atoms. The last fact should lead to an increase in the lengths of $\mathrm{Ca}_{(2)}-\mathrm{O}$ bonds.

Secondly, an increase in electronegativity of anions located on sixth-order axes is accompanied by a decrease in the volume of the unit cell and, consequently, a decrease in all bond lengths, including $\mathrm{Ca}_{(2)}-\mathrm{O}$ lengths. As we can see, the above two factors compete with each other; therefore, the length of the bond will be determined by which of the factors will be dominant. For short $\mathrm{Ca}_{(2)}-\mathrm{O}$ bond lengths, namely, $\mathrm{Ca}_{(2)}-\mathrm{O}_{(3)}$ and $\mathrm{Ca}_{(2)}-\mathrm{O}_{(2)}$ bonds, the first factor is dominant. Therefore, there is a tendency to decrease $\mathrm{Ca}_{(2)}-\mathrm{O}_{(3)}$ and $\mathrm{Ca}_{(2)}-\mathrm{O}_{(2)}$ bond lengths as the electronegativity of anions located on the sixth-order axes decreases. At the same time, for longer $\mathrm{Ca}_{(2)}-$ $\mathrm{O}_{(3) b}$ and $\mathrm{Ca}_{(2)}-\mathrm{O}_{(1)}$ bonds, the second factor is dominant. Moreover, an increase in the $\mathrm{Ca}_{(2)}-\mathrm{O}_{(1)}$ bond length with a decrease in the electronegativity of anions located on the sixth-order axes turns out to be significant. Thus, for example, the replacement of all fluorine atoms with chlorine atoms in the structure of calcium fluoroapatite 
TABLE. The bond lengths of apatites of the $\mathrm{Ca}_{10}\left(\mathrm{PO}_{4}\right)_{6} X_{2}$ form, where $X=\mathrm{F}, \mathrm{Cl}, \mathrm{OH}$, obtained because of the relaxation of atomic positions inside the unit cells with fixed experimental lattice parameters.

\begin{tabular}{ccccc}
\hline Compound Bond & $\mathrm{Ca}_{10}\left(\mathrm{PO}_{4}\right)_{6} \mathrm{~F}_{2}$ & $\mathrm{Ca}_{10}\left(\mathrm{PO}_{4}\right)_{6} \mathrm{Cl}_{2}$ & $\mathrm{Ca}_{10}\left(\mathrm{PO}_{4}\right)_{6}(\mathrm{OH})_{2}$ \\
\hline $\mathrm{P}-\mathrm{O}_{(1)}, \AA$ & 1.551 & 1.549 & 1.557 \\
$\mathrm{P}-\mathrm{O}_{(2)}, \AA$ & 1.562 & 1.564 & 1.565 \\
$\mathrm{P}-\mathrm{O}_{(3)}, \AA$ & 1.554 & 1.552 & 1.561 \\
$\mathrm{O}_{(1)}-\mathrm{O}_{(2)}, \AA$ & 2.568 & 2.560 & 2.582 \\
$\mathrm{O}_{(1)}-\mathrm{O}_{(3)}, \AA$ & 2.563 & 2.586 & 2.571 \\
$\mathrm{O}_{(2)}-\mathrm{O}_{(3)}, \AA$ & 2.519 & 2.482 & 2.519 \\
$\mathrm{O}_{(3)}-\mathrm{O}_{(3)}, \AA$ & 2.502 & 2.522 & 2.527 \\
$\mathrm{Ca}_{(1)}-\mathrm{O}_{(1)}, \AA$ & 2.394 & 2.410 & 2.405 \\
$\mathrm{Ca}_{(1)}-\mathrm{O}_{(2)}, \AA$ & 2.448 & 2.396 & 2.450 \\
$\mathrm{Ca}_{(1)}-\mathrm{O}_{(3)}, \AA$ & 2.806 & 2.771 & 3.938 \\
$\mathrm{Ca}_{(2)}-\mathrm{O}_{(3)}, \AA$ & 2.341 & 2.306 & 2.822 \\
$\mathrm{Ca}_{(2)}-\mathrm{O}_{(2)}, \AA$ & 2.356 & 2.250 & 2.422 \\
$\mathrm{Ca}_{(2)}-\mathrm{O}_{(3) b}, \AA$ & 2.471 & 2.511 & 2.454 \\
$\mathrm{Ca}_{(2)}-\mathrm{O}_{(1)}, \AA$ & 2.722 & 2.984 & 2.388 \\
$\mathrm{Ca}_{(2)}-X, \AA$ & 2.306 & 2.589 & 2.633 \\
$\mathrm{O}_{(1)}-\mathrm{O}_{(1) c}, \AA$ & 2.891 & 3.029 & 2.897 \\
$\mathrm{O}_{(1)}-\mathrm{O}_{(3)}, \AA$ & 2.944 & 3.002 & 2.953 \\
$\mathrm{O}_{(2)}-\mathrm{O}_{(3) c}, \AA$ & 2.932 & 2.915 & 2.931 \\
$\mathrm{O}_{(2)}-\mathrm{O}_{(2)}, \AA$ & 3.049 & 2.884 & 2.978 \\
$\mathrm{O}_{(3)}-\mathrm{O}_{(3)}, \AA$ & 3.076 & 3.178 & 3.039 \\
$\mathrm{Ca}_{(2)}-\mathrm{P}, \AA$ & 3.096 & 3.065 & 3.025 \\
\hline
\end{tabular}

is accompanied by an increase in the $\mathrm{Ca}_{(2)}-\mathrm{O}_{(1)}$ bond length by 0.26 Å.

For $\mathrm{Ca}_{(2)}-X$ bond lengths, the following trend is recorded. The distance $\mathrm{Ca}_{(2)}-X$ decreases with increasing electronegativity of anions located on the sixth-order axes. The $\mathrm{O}-\mathrm{O}_{\text {(neighbouring tetrahedron) }}$ lengths determine the interaction of tetrahedra with each other. There are only five such links: $\mathrm{O}_{(1)}-\mathrm{O}_{(1) c}, \mathrm{O}_{(1)}-\mathrm{O}_{(3) c}, \mathrm{O}_{(2)}-\mathrm{O}_{(3) c}, \mathrm{O}_{(2)}-\mathrm{O}_{(2) c}$ and $\mathrm{O}_{(3)}-\mathrm{O}_{(3) c}$. Different apatites of the $\mathrm{Ca}_{10}\left(\mathrm{PO}_{4}\right)_{6} X_{2}$ series, where $X=\mathrm{F}, \mathrm{Cl}, \mathrm{OH}$, are characterized by a different arrangement on the length scale of the above bonds.

Born effective charges of phosphorus atoms increase in a series of compounds $\mathrm{Ca}_{10}\left(\mathrm{PO}_{4}\right)_{6} \mathrm{~F}_{2} \rightarrow \mathrm{Ca}_{10}\left(\mathrm{PO}_{4}\right)_{6}(\mathrm{OH})_{2} \rightarrow \mathrm{Ca}_{10}\left(\mathrm{PO}_{4}\right)_{6} \mathrm{Cl}_{2}$,. The tensors of the effective Born charges of oxygen atoms have a significant deviation from isotropy. The effective charge of oxygen atoms ranged from -2.7 to -1.3 electron charge for different directions of motion. For apatites of the $\mathrm{Ca}_{10}\left(\mathrm{PO}_{4}\right)_{6} X_{2}$ form, where $X=\mathrm{F}, \mathrm{OH}, \mathrm{Cl}$, 
the $\mathrm{O}_{(1) x x}$ component turned out to be larger than $\mathrm{O}_{(1) z z}$, and the difference ranged from 0.65 to 0.85 electron charge, i.e. changed insignificantly during the transition from one type of apatite to another. A similar situation was observed for $\mathrm{O}_{(2)}$ atoms, i.e. $\mathrm{O}_{(2) x x}$ turned out to be larger than $\mathrm{O}_{(2) z z}$, and the difference also changed insignificantly during the transition from one type of apatite to another.

For the third non-equivalent oxygen atom, the opposite picture was established. The components $\mathrm{O}_{(3) x x}$ turned out to be significantly less than $\mathrm{O}_{(3) z z}$, for apatites of the $\mathrm{Ca}_{10}\left(\mathrm{PO}_{4}\right)_{6} \mathrm{X}_{2}$ form, where $X=\mathrm{F}$, $\mathrm{OH}, \mathrm{Cl}$. The tensors of the effective Born charges of the $\mathrm{X}$ atoms located on the $c$ axes have significant deviations from isotropy.

The elastic constants of the compounds under study were obtained. The phosphorus-oxygen interaction is very strong, because the longitudinal component of force tensor varies in the range of large values from 0.506 to $0.423 \mathrm{kN} \cdot \mathrm{m}^{-1}$. The transverse components for these interactions are significantly smaller than the longitudinal components (five times), which means the directionality of the force interaction along the $\mathrm{P}-\mathrm{O}$ bond. The off-diagonal components of the force tensor are very small compared to the diagonal components, which also indicates the covalence of the phosphorusoxygen bond.

For the compound $\mathrm{Ca}_{10}\left(\mathrm{PO}_{4}\right)_{6} \mathrm{~F}_{2}$, when fluorine is replaced by chlorine or a hydroxyl group, the interaction of phosphorus with the nearest oxygen environment changes only slightly. Thus, there is a tendency to decrease the longitudinal component of force tensor of interatomic interaction while decreasing electronegativity of anion $\mathrm{X}$, which is more pronounced for the first and second nonequivalent oxygen atoms. It would seem that phosphorus is surrounded by oxygen atoms on all sides that makes it difficult to interact with calcium atoms. However, phosphorus-calcium interaction was quite strong. Thus, the longitudinal component changed from 0.064 to $0.058 \mathrm{kN} \cdot \mathrm{m}^{-1}$, wherein decreased with decreasing electronegativity of the anion located on the $c$ axis. The transverse components of this force tensor were also significantly smaller than the longitudinal components that indicates the covalent phosphorus-calcium bond type and the direction of interaction along the bond line. It is interesting that the oxygen atom of the neighbouring tetrahedron is slightly farther from the phosphorus atom than the calcium atom (only 0.1-0.2 $\AA$ ), but the force constants for the bond phosphorus-oxygen (neighbouring tetrahedron) are substantially less than the corresponding force constants for the bond $\mathrm{P}-$ $\mathrm{Ca}_{(2)}$. Thus, the interaction of phosphorus-oxygen (neighbouring tetrahedron) is weak. Consequently, these facts confirm the existence of a long-range interaction of calcium with surrounding atoms due to the presence of a two-valley effective $3 d$-electrons potential 
with a localization of the second valley of about $3.0 \AA$.

Oxygen atoms constitute the atomic environment of the $\mathrm{Ca}_{(1)}$ atom, and for calcium fluor- and hydroxoapatite, the nearest to the first non-equivalent position of the calcium atom is the $\mathrm{O}_{(1)}$ atom, while for calcium chloroapatite, the $\mathrm{O}_{(2)}$ atom is the closest. A change in the oxygen environment for calcium chlorapatite in comparison with fluor- and hydroxy-analogs leads to a significant change in the nature of the oxygen-calcium bonds. The longitudinal force constants of these bonds for calcium fluor- and hydroxyapatites were small and amounted to -0.022 and $0.016 \mathrm{kN} \cdot \mathrm{m}^{-1}$, respectively. At the same time, the transverse components of force tensor turned out to be not much less and equal to -0.012 and -0.012 $\mathrm{kN} \cdot \mathrm{m}^{-1}$. Thus, for calcium fluor- and hydroxyapatites, the $\mathrm{Ca}_{(1)}-\mathrm{O}_{(1)}$ interaction is weak, and the connection is not clearly pronounced as directional, i.e. ionic one.

The interaction of the calcium atom of the second non-equivalent position with the anion located on the $\mathrm{c}$ axis increases in the series of compounds $\mathrm{Ca}_{10}\left(\mathrm{PO}_{4}\right)_{6} \mathrm{~F}_{2} \rightarrow \mathrm{Ca}_{10}\left(\mathrm{PO}_{4}\right)_{6}(\mathrm{OH})_{2} \rightarrow \mathrm{Ca}_{10}\left(\mathrm{PO}_{4}\right)_{6} \mathrm{Cl}_{2}$. In addition, for the calcium fluor- and hydroxyapatite, the transverse component of the force constants is three times smaller than the longitudinal, i.e. the bond is partially ionic and partially covalent. When anion on the $c$ axis is replaced by chlorine, the transverse component decreases sharply and the longitudinal component increases that means an increase in the covalent component of the $\mathrm{Ca}_{(2)}-X$ bond.

\section{CONCLUSIONS}

The theoretically calculated X-ray emission bands of the $\mathrm{O} K_{\alpha^{-}}$and $\mathrm{Ca} K_{\beta}$-bands in the calcium apatite were in good agreement with the experimental spectra. For the $L_{I I, I I I}$-bands of calcium in the $\mathrm{Ca}_{10}\left(\mathrm{PO}_{4}\right)_{6} \mathrm{~F}_{2}$ compound, the agreement between the theoretical and experimental curves was a bit worse, which indicates the need to take into account relativistic corrections that make it possible to calculate the difference in the shape of the $L_{I I}$ and $L_{I I I}$ bands. Some discrepancy between the theoretical and experimental forms of the $\mathrm{P} K_{\beta}$ bands in $\mathrm{Ca}_{10}\left(\mathrm{PO}_{4}\right)_{6}(\mathrm{OH})_{2}$ is caused by the small radius of the MT-sphere of phosphorus and, as a result, not taking into account the electron density of phosphorus, which is outside the sphere. The difference in the forms of the curves between the theoretical and experimental $\mathrm{F} K_{\beta}$ bands in the compound $\mathrm{Ca}_{10}\left(\mathrm{PO}_{4}\right)_{6} \mathrm{~F}_{2}$ is due to a significant underestimation by the calculation of the covalent component of the $\mathrm{Ca}-\mathrm{F}$ bond.

The presence of an ordered structure of oxygen tetrahedra in apatite is a canonically decisive parameter in the formation of the 
form and the main features of the curve of the total density of electronic states of calcium apatites.

In various calcium compounds, atomic effects play a significant role in shaping the shape of the $L_{\alpha}$-spectra of calcium and, as a result, the participation of $d$-states of calcium in bond formation is levelled by their significant localization, apparently, in the inner valley of effective potential.

Due to the peculiarities of the electronic structure of calcium and a limited choice of MT-spheres, quantum-mechanical calculations using the density functional theory methods cannot fully describe the long-range component of calcium interaction with the surroundings, however, the presence of a number of experimental data indicate that the stability of the apatite structure is largely determined by the two-valley effective potential of calcium $d$-electrons.

\section{ACKNOWLEDGMENT}

The work was carried out within the framework of the target program of scientific research of the Department of Physics and Astronomy of the National Academy of Sciences of Ukraine 'Study of fundamental physical and astronomical processes and prospects for their practical application' KPKBK 6541230-1A.

\section{REFERENCES}

1. V. L. Karbovskiy and A. P. Shpak, Apatity i Apatitopodobnyye Soyedineniya. Elektronnoye Stroenie i Svoistva (Kyiv: Naukova Dumka: 2010) (in Russian).

2. A. P. Shpak, V. L. Karbovskiy, and V. V. Trachevskyy, Apatite (Kyiv: Akademperiodika: 2002) (in Russian).

3. T. Kanazawa, Neorganicheskie Fosfatnyye Materialy (Kyiv: Naukova Dumka: 1998) (in Russian).

4. K. Sato, Y. Suetsugu, J. Tanaka, S. Ina, and H. Monma, J. Col. Int. Sci., 224, No. 1: 23 (2000); https://doi.org/10.1006/jcis.1999.6623.

5. J. Y. Kim, R. R. Fenton, B. A. Hunter, and B. J. Kennedy, Aust. J. Chem., 53, No. 8: 679 (2000); https://doi.org/10.1071/CH00060.

6. P. A. Henning, M. Moustiakimov, and S. Lidin, J. Solid State Chem., 150, No. 1: 154 (2000); doi: 10.1006/jssc.1999.8571.

7. V. S. Sobolev, Fizika Apatita (Novosibirsk: Nauka: 1975) (in Russian).

8. R. Y. Karazyia, Uspekhi Fiz. Nauk, 135, No. 1: 79 (1981) (in Russian).

9. B. B. Kadomtsev and M. B. Kadomtsev, Uspekhi Fiz. Nauk, 166, No. 6: 651 (1996) (in Russian).

10. R. E. Ruus, A. A. Maiste, and Yu. A. Maksymov, Yzv. AN SSSR, 46, No. 4: 789 (1982) (in Russian).

11. F.-Ch. Kühl, M. Müller, M. Schellhorn, K. Mann, S. Wieneke, and K. Eusterhues, J. Vac. Sci. Technol., A 34: 041302 (2016); doi: $10.1116 / 1.4950599$. 
12. J. Y. Peter Ko, X.-T. Zhou, F. Heigl, T. Regier, R. Blyth, and T.-K. Sham, AIP Conf. Proceed., 882: 538 (2007); https://doi.org/10.1063/1.2644585.

13. J. Cosmidis, K. Benzerara, N. Nassif, T. Tyliszczak, and F. Bourdelle, Acta Biomaterialia, 12, No. 15: 260 (2015); https://doi.org/10.1016/j.actbio.2014.10.003.

14. M. E. Fleet and X. Liu, Amer. Mineral., 94, Nos. 8-9: 1235 (2009); doi: 10.2138/am.2009.3228.

15. S. K. Lee, P. J. Eng, and Ho Mao, Rev. Mineral. Geochem., 78, No. 1: 139 (2014); https://doi.org/10.2138/rmg.2014.78.4.

16. R. A. Metzler and P. Rez, J. Phys. Chem. B, 118, No. 24: 6758 (2014); doi: $10.1021 /$ jp503565e.

17. P. S. Miedema, H. Ikeno, and F. M. de Groot, J. Phys. Condens. Matter., 23, No. 14: 145501 (2011); doi: 10.1088/0953-8984/23/14/145501.

18. S. J. Naftel, T. K. Sham, Y. M. Yiu, and B. W. Yates, J. Synchrotron Rad., No. 8: 255 (2001); https://doi.org/10.1107/S0909049500019555.

19. D. L. Proffit, T. T. Fister, S. Kim, B. Pan, Ch. Liao, and J. T. Vaugheya, J. Electrochem. Soc., 163, No. 13: A2508 (2016); doi: 10.1149/2.0121613jes.

20. G. Geng, R. J. Myers, A. D. Kilcoyne, J. Ha, and P. J. M. Monteiro, Am. Min., 102: 900 (2017); doi 10.2138/am-2017-5670.

21. J. Vinson and J. J. Rehr, Phys. Rev. B, 86: 195135 (2012); https://doi.org/10.1103/PhysRevB.86.195135.

22. V. V. Nemoshkalenko, Vybrani Pratsi (Kyiv: Akademperiodyka: 2003), vol. 1: 89 (in Russian).

23. P. Wu, Y. Z. Zeng, and C. M. Wang, Biomaterials, 25: 1123 (2004); https://doi.org/10.1016/S0142-9612(03)00617-3. 